53. The authors are grateful to the nurses of the Clinical Research Center for their invaluable assistance, to Dr. Won $\mathrm{Ng}$. Division of Medical Genetics for measuring HGPRTase activity and incorporation of $\left[U-{ }^{14} \mathrm{C}\right]$ glycine into uric acid, to Ms. Betty Knoch and Ms. Carol Kanter for their expert technical assistance and to Mrs. Sue Platt for her secretarial help.

54. This research was supported in part by a grant from the General Clinical
Research Centers Program (RR-86) of the Division of Research Resources, National Institutes of Health.

55. Requests for reprints should be addressed to: T. Roe, M.D., P.O. Box 54700, Terminal Annex, Los Angeles, Calif. 90054 (USA).

56. Received for publication June 21, 1976.

57. Accepted for publication October 1, 1976

\title{
Enzymic Differentiation of Human Liver: Comparison with the Rat Model
}

\author{
OLGA GREENGARD(70) \\ Deparment of Biological Chemistry, Harvard Medical School, and the Cancer Research Institute, New England \\ Deaconess Hospital, Boston, Massachusetts, USA
}

\section{Summary}

The quantitative pattern of enzymes in the second trimester human fetal liver is significantly different from that of adult liver. For some 20 enzymes, the activity quotient (AQ,i.e., activity of immature liver divided by that in adult liver) is appreciably different from 1.0. Most of the enzymes increase their concentrations with age but, as one would expect, some contribute to differentiation by diminishing in amount.

In developing human liver the concentrations of the various enzymes tend to change in the same direction as they do in rat liver. Those that increase in rat liver have been classified into three main clusters, according to whether their rise begins on about the 17th day of gestation (B), the first neonatal day (C), or just before weaning (D), respectively. The distribution of these enzymes among these three clusters correlates with their AQ's in the human fetal liver. In general, enzymes with $A Q$ around 0.5 belong to cluster (B) in rat liver whereas those with 0-0.16 belong to cluster $\mathrm{C}$ or $\mathrm{D}$.

Gross malformations resulting from the teratogenic action of drugs, hormones, or vitamins on the early embryo attract much attention. The harmful impacts of such agents at late stages of gestation are less spectacular. They may be more frequent, however, and manifest themselves in permanent inadequacies in metabolism or growth with a tendency to succumb to minor childhood diseases. The underlying causes may not be mirrored in the cytocomposition or even the subcellular morphology of autopsy specimens. Only deviations from the organ characteristic quantitative pattern of gene products would provide sensitive enough indictors of the metabolic lesions and of the aberrant aspects of differentiation that were responsible for them. In both the presence and absence of detectable morphologic abnormalities, the study of enzymes, this most varied and largest class of specific chemical constituents, would greatly extend the resolving power of the usual diagnostic procedures postmortem.

\section{Speculation}

The sequence in which different enzymes approach their adult concentration in human liver closely resembles that in rat liver.
This suggests that the mechanisms responsible for the schedule of gene expression must also be analogous: the synthesis of specific groups of enzymes at each corresponding critical period is regulated by the same hormones in both species. Hence, the "enzyme pathology" of infant livers not only specifies basic metabolic lesions: aided by observations on the rat model, it could also identify the age of onset and the kind of aberrations in the fetal environment which initiated the lesions.

Long before the elucidation of the nature of gene action, Needham (1931) (48) perceived the central importance of the changing profile of specific proteins in embryonic development. He felt, however, that proper use of enzymes as indicators of tissue differentiation would have to await the availability of less ambiguous and more sensitive assay techniques. The ambiguity, namely, whether the activity assays are supposed to reflect the catalytic efficiency or the amounts of enzymes, began to be resolved in the 1950's. After Knox's discovery of adaptive enzyme synthesis in mammalian tissues (35), methods were developed for measuring changes in the amounts of enzymes (the primary regulators of physiologic function) as distinct from fluctuations in their activity (a superimposed fine control). It soon became apparent that even during late fetal and postnatal development the differentiation of tissue functions depended to a large extent on the synthesis of enzymes de novo and not merely on the activation of those already present in the embryo $(30,38$, 49). Indications were obtained that in man, too (40), some hepatic enzymes may still be absent at term. A certain flexibility in time schedule was first suggested by experiments in which the synthesis of a hepatic enzyme was enhanced or delayed by preor postmature delivery $(8,49)$, and that of an intestinal enzyme by changes in endocrine status (46). The relevance of these early findings to the frequently observed functional deficiencies in apparently normal newborn infants (9) was one stimulus for extensive biochemical research on tissues of developing mammals. These confirmed that the enzymic profiles that are to distinguish mature tissues from one another continue to evolve and to undergo drastic changes long after these tissues have become morphologically distinct. During this postembryonic de- 
velopment, enzyme pathology, the analysis of quantitative patterns of enzymes, can provide the most sensitive and objective criteria for normal tissue differentiation $(17,36)$.

In rat liver, the model extensively studied in this laboratory, the late fetal and early postnatal period is punctuated by sudden drastic steps in the evolution of biochemical composition whereas the cytomorphometric changes (measured under the light or electron microscope $(19,24)$ ) are gradual, relatively unimpressive, and do not necessarily mirror major deviations in the normal schedule of enzymic development. Recognition of the fact that new enzymes emerge in clusters (16) at times following specific alterations in the physiologic state of the organism facilitated the identification of some natural stimuli of sequential gene expression. The administration of appropriate hormones, substrates, or drugs can either evoke precociously or delay the synthesis of several subclusters of enzymes. This sensitive responsiveness to experimental interference suggests that alterations in the normal schedule of gene expression might often occur "spontaneously" (due to minor alterations of the fetal environment), but that means could be found to prevent or reverse them.

The pressing question we now have to explore is whether the "rat model" is applicable to man. Is there a species analogy in the overall pattern of hepatic biochemical differentiation? Are the discoveries about the mechanisms underlying this process in the rat pertinent to man? There are no comprehensive reviews in the literature about the enzymic composition of developing human liver; in the numerous original papers the kind of quantitative data needed to answer these questions is restricted to a small spectrum of enzymes. To extend this spectrum, our laboratory has recently determined the concentration of 15 enzymes in normal adult and fetal liver. They were not chosen on the basis of possible functional importance (although several metabolic pathways are represented) but in the hope of encompassing a spectrum of "developmental behaviors," i.e., that which includes enzymes with both "early" and "late" emergence, and also some that may contribute to differentiation by decreasing in amount. These results, collated with comparable literature data on 15 additional enzymes, some also studied in neonatal liver, will provide the basis for this attempted overview of biochemical differentiation in human liver.

\section{QUANTIFICATION OF ENZYMES}

The enzymes to be discussed here were quantified in vitro using assay mixtures supplemented with saturating amounts of the appropriate substrates and cofactors. In such "optimal" systems, catalytic rate (unit = micromole of product formed per min) is limited only by the volume of tissue extract added and is proportional to the amount of enzyme in the extract. Hence "activity" (given in units per g) is used synonymously with "concentration" or "Ievel." It should be noted that the units per g have no absolute meaning; they are used to compare the concentration of the enzyme in one tissue relative to others or to the same tissue at another stage of development. However, an additional consideration enters enzyme studies of immature tissues. For example, depending on whether the adult tissue contains 5 or 100 units/g, an increase during fetal life from $1-5$ units denotes either an important or a very minor step in differentiation. The concentration in fetal or neonatal liver must therefore be judged against the physiologically meaningful endpoints provided by the concentration of the same enzymes in the normal, adult liver of the same species. Expression of the result in the form of the following quotient, $\mathrm{AQ}$, serves this purpose.

$$
\mathrm{AQ}=\frac{\text { units per } \mathrm{g} \text { immature liver }}{\text { units per } \mathrm{g} \text { adult liver }}
$$

A series of such AQ's, for any particular stage of development, show at a glance the direction (increase or decrease) and end extent of concentration change that the various enzymes are to undergo during subsequent maturation. Comparison of the developing liver of two different species also cannot be based on the absolute activities of the enzymes but on their relation to those in the appropriate adult liver, i.e., on the two sets of AQ's, one for each species.

The assay of an enzyme, with different methods (based on equally acceptable principles) or with even small modifications of a standard method, can yield varying absolute activities. Therefore, a report in the literature on an enzyme in one tissue (e.g., human fetal liver) cannot be directly compared with that for another tissue (e.g., human adult liver) obtained in another laboratory. This wastage of information can be circumvented if both studies include concomitant analysis of a standard tissue such as the easily obtainable normal, adult rat liver (36). After standardization (i.e., division by the activity in the adult rat liver), $A Q$ can be calculated using the numerator from one laboratory and the denominator from another. Such economy is particularly important in studies on man; data reported together with adult rat liver values (as in Table 1) can be integrated with future (similarly standardized) measurements at additional stages of development without having to redetermine them at the ages already covered. (No conclusions will be drawn from the absolute activities in human versus rat liver. For some enzymes activities are lower, for others higher; it is merely of some practical importance that activities in the two species did not differ by orders of magnitude so that it was not necessary to adjust the sensitivity of the assay methods.)

It follows from the purely relative meaning of enzyme quantifications that comparisons of the absolute activities of different enzymes (without appropriate metabolic studies in vivo) in a tissue can lead to no biologically valid conclusions. A major difference in units per g between two enzymes should not be assumed to mean a similar difference in the rate at which they metabolize their respective substrates in vitro. What we intend to compare is the developmental behavior of different enzymes, based on their respective AQ's.

When dealing with quotients such as $\mathrm{AQ}$, a uniform tissue base is as important as is the normalization of the units of catalytic rate-the unambiguous $1 \mathrm{~g}$ wet weight is preferable to variable bases such as protein ( $\mathrm{mg}$ protein per $\mathrm{g}$ adult and immature liver will be tabled) or DNA. The latter, as shown for developing rat liver (19), can be particularly misleading. When the erythropoietic elements (representing a small portion of the total mass) involute, or when the hepatocytes themselves enlarge, there is a considerable decrease in cell number (and therefore in DNA) per $\mathrm{g}$. The amounts of many cytoplasmic enzymes, if expressed per mg DNA (or per cell), increase, of course, at these times. However, if the enzymes rise in parallel and remain constant per $\mathrm{mg}$ protein, the associated functional attributes of the hepatocytic cytoplasm are unaltered. Significant events in biochemical differentiation are signaled by enzymes which undergo major, disproportionate changes, i.e., whose concentrations rise or fall per g hepatocytic mass.

\section{BIOCHEMICAL IMMATURITY OF HUMAN FETAL AND NEO- NATAL LIVER}

The biochemical data on fetal liver are summarized in Table 1. The age at which the immaturity of fetal liver is to be assessed will be referred to as "midgestation." Many of the enzymes have been measured as early as the 8 th and as late as the 28 th week. Only a single, mean value is given for each enzyme: none showed appreciable, consistent variation with age (see "Fetal age, weeks" in column 2 of Table 1) indicating that the enzymic composition does not undergo major steps of maturation during this fetal period. It must be emphasized that this conclusion refers to liver only. In alternate tissues, e.g., brain, critical steps in functional differentiation may occur during a portion of the very period considered here.

Since the concentrations of even randomly selected enzymes have been shown to distinguish mature tissues from each other, and from their more or less undifferentiated variants (normal or 
Table 1. Developmental changes in hepatic enzyme levels

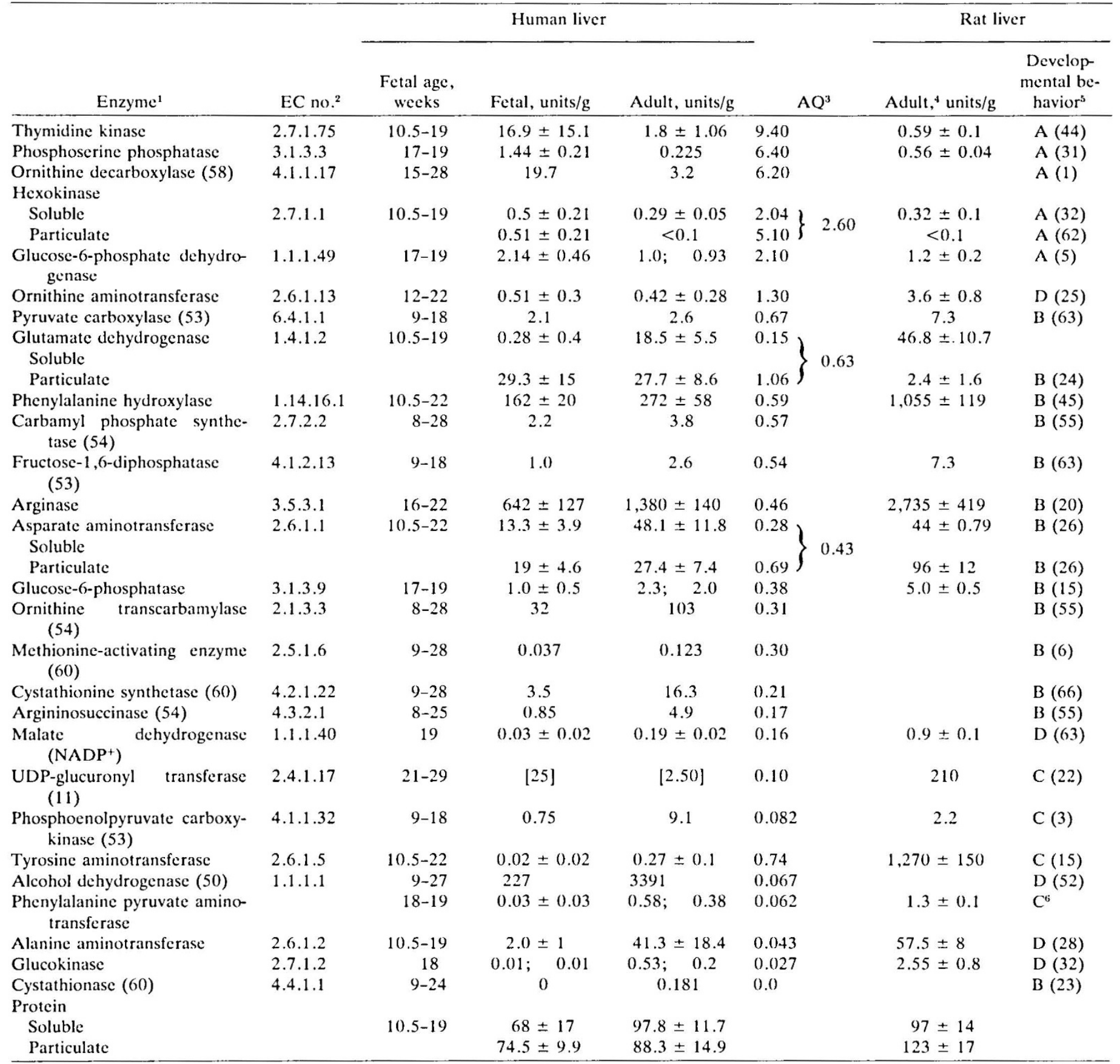

' Enzymes without reference numbers were assayed in this laboratory (for provenance of specimens see Herzfeld et al (28); DelValle and Greengard, unpublished data) by methods given in the last column. The values refer to individual livers or to means \pm SD of results with 3-10 livers; activities in the standard tissue, adult rat liver, were assayed simultaneously. Data for the other enzymes (see references within parentheses) are taken from the literature, when necessary converted to standard units (micromoles per min) per g; undefined units are within brackets.

2 These numbers were taken from Enzyme Nomenclature: Recommendations (1972) of the International Union of Pure and Applied Chemistry and the International Union of Biochemistry, American Elsevier Publishing Co., New York, 1973.

${ }^{3} \mathrm{AQ}$ was calculated as described in the text; for enzymes measured separately in the soluble and particulate fractions of liver homogenates AQ is given for each and for the sum.

${ }^{4}$ Values for adult rat liver are shown if reported in the same publication.

${ }^{5}$ The "Developmental behavior" of rat liver enzymes, denoted by letters explained in the text and in Figure 1, was based on the data from references within parentheses.

${ }^{6}$ Sanchez, unpublished data.

neoplastic (36)), let us at first disregard the names of the enzymes in Table 1, or notions about their functional importance, and inspect only the "AQ" column. It may be seen that for some 20 out of the 23 enzymes, the AQ is appreciably different from 1.0. Most of the enzymes increase their concentrations with age but, as one would expect, some (see $A Q>1.0$ ) contribute to differentiation by diminishing in amount.

Our first conclusion thus is that the quantitative pattern of enzymes in the second trimester fetal liver is significantly different from that of adult liver. To characterize the nature of this 
immaturity and its possible functional corollaries, we must look at individual enzymes (with the reservation that their "names" or catalytic properties by which we recognize them in vitro do not always specify their physiologic role). Not surprisingly, the fetal liver, like all growing tissues, is still rich in enzymes necessary for the synthesis of DNA (thymidine kinase), polyamines (ornithine decarboxylase), pentoses (glucose-6-phosphate dehydrogenase), nonessential amino acids (phosphoserine phosphatase), and for extensive energy production via glycolysis (hexokinase). The $A Q$ of a large number of enzymes (those in the center of Table 1), many concerned with amino acid metabolism, is around (0.5. Glucose-6-phosphatase, as previously shown (57), is also in this category. An even more clear-cut physiologic immaturity is reflected by the absence of appreciable levels of enzymes (towards the end of Table 1) subserving important hepatic functions such as gluconeogenesis (phosphoenolpyruvate carboxykinase), NADPH production for fatty acid synthesis (malic enzyme), and detoxications via glucuronyl formation. Similarly low were the levels of some enzymes which metabolize amino acids, tyrosine aminotransferase (also shown by Vogel et al . (65)), cystathionase, and alanine aminotransferase.

Several more enzymes, especially those on pathways not represented in Table 1 , need to be quantified to obtain a more complete picture about the metabolic potentialities of the midgestation liver. Such information, especially when extended to additional tissues, would help to predict specific functional difficulties which premature babies may encounter. However, more complete time curves are necessary for other purposes, such as defining the gestational age at which the genetic absence of various enzymes would become manifested. We cannot tell, for example, the earliest age at which the absence of phenylalanine hydroxylase distinguishes the liver of the normal from that of the phenylketonuric organism (although by the 11 th week a deficiency in this enzyme could be detected much more easily than one in, for example, tyrosine aminotransferase (DelValle and Greengard, unpublished data)).

The subeellular distribution of enzymes may also contribute to the characterization of the immaturity of fetal liver. Examp.es of this are hexokinase and glutamate dehydrogenase (see Table 1). In fetal liver a greater portion of these enzymes is in the particulate than in the soluble fraction. However, adult liver contains very little particulate hexokinase and the ratio of particulate to soluble glutamate dehydrogenase is only 1.5 (as opposed to 110 in the adult). Less impressive is the change with age in the distribution of aspartate aminotransferase from a predominantly particulate to a predominantly soluble one.

The protein content of the soluble and particulate fractions of liver increased somewhat with age but very much less so than did the concentrations of the enzymes (sec last 18 major entries in Table 1). Hence, conclusions about the biochemical immaturity of the fetal liver would be similar if the AQ had been calculated from enzyme concentrations expressed per mg (total, soluble, or particulate) protein instead of per g wet weight.

It would be of great interest to compare the biochemical maturity of human liver at midgestation with that at term, but only a few investigations encompass both stages of development. Measurements in neonatal liver are often reported without those on a standard tissue or on human adult liver so that, in view of the variability of activities, we cannot compare them with fetal values from different laboratories. The enzymes in Table 2 were, however, studied systematically in several specimens at various fotal as well as postnatal stages. It may be seen that the AO for all nine enzymes is well below 1.0, indicating that the hepatic enzyme pattern is still immature at term.

Since these enzymes were not selected for the purpose of demonstrating that the liver undergoes little differentiation between midgestation and term, it is remarkable that for all of them the AQ in the neonate is identical with or only slightly above that in the fetal liver. Preliminary studies in this laboratory indicate that declines in enzymes (those with AQ's above 1.0 in Table 1$)$ may be the main events during this relatively silent, late fetal period of differentiation. Aspects of the data in Table 2, relevant to species comparisons and physiologic regulation, will be discussed in the next two sections.

\section{COMPARISON OF HEPATIC ENZYMIC DIFFERENTIATION IN MAN AND RAT}

In rat liver a large number of enzymes, including those in Tables 1 and 2, have been quantified at frequent intervals through fetal and postnatal life. Such complete "developmental histories" which would reveal the exact age of abrupt change in concentration are, of course, not available for human liver. But even with values for only one fetal period in man we can compare the direction in which the concentration of different enzymes change with age in the two species. Enzymes denoted by letter $A$ in the last column in Table 1 are the ones which decrease in rat liver during late fetal or neonatal development, and it may be seen that these are also the ones with AQ's well over 1.0 in human fetal liver. One enzyme among these, hexokinase, exhibits an additional species analogy since in rat too, much of it is in the particulate fraction of the fetal but not the adult liver (53).

The enzymes in Table 1 labeled by letters other than $A$ are the ones whose concentrations undergo a considerable increase in developing rat liver at some time after the 17 th day of gestation;

Table 2. Enzyme levels in newborn liver

Rat liver

\begin{tabular}{|c|c|c|c|c|c|}
\hline \multirow[b]{2}{*}{ Enzymc 1} & \multirow[b]{2}{*}{ EC. no. } & \multirow[b]{2}{*}{$\begin{array}{l}\text { Newborn human } \\
\text { liver, } \mathrm{AQ}\end{array}$} & \\
\hline & & & -3 days, $A Q$ & Newborn, 2 AQ & $\begin{array}{l}\text { Developmental be- } \\
\text { havior }\end{array}$ \\
\hline Carbamyl phosphate synthetase $(54,55)$ & 2.7 .2 .2 & 0.58 & 0.038 & 0.38 & $B^{2}$ \\
\hline Ornithine transcarbamylase $(54,55)$ & 2.1 .3 .3 & 0.45 & 0.12 & 0.39 & $B^{2}$ \\
\hline Arginosuccinase $(54,55)$ & 4.3 .2 .1 & 0.54 & 0.04 & 0.33 & $\mathrm{~B}^{2}$ \\
\hline Arginase $(54,55)$ & 3.5 .3 .1 & 0.46 & 0.06 & 0.32 & $B^{2}$ \\
\hline Cystathionine synthetase $(60,66)$ & 4.2 .1 .22 & 0.53 & 0.12 & 0.59 & $\mathrm{~B}^{2}$ \\
\hline Phenylalanine hydroxylase $(45,51)$ & 1.14 .16 .1 & 0.51 & 0.0 & 0.30 & $\mathrm{~B}^{2}$ \\
\hline Cystathionase $(13,23)$ & 4.4 .1 .1 & $0-0.67$ & 0.125 & 1.0 & $\mathrm{~B}^{\prime}$ \\
\hline Alcohol dehydrogenase $(50,52)$ & 1.1 .1 .1 & 0.15 & 0.09 & 0.22 & $\mathrm{C}$ \\
\hline Phosphoenolpyruvate carboxykinase $(53,63)$ & 4.1 .1 .32 & $0.11^{3} ; 0.42^{4}$ & 0.0 & $05 ; 1.0^{4}$ & $\mathrm{C}$ \\
\hline
\end{tabular}

${ }^{1}$ The provenance of the data for man and rat is indicated by the first and second reference, respectively. When necessary the enzyme units were converted to micromoles per min per g. AQ's were calculated from the immature and the adult values given in the same publication.

2 Unless indicated by superseripts 4 or 5 , newborn rats were 1 day old.

${ }^{3}$ Seventh month of gestation.

4 Two days after birth.

${ }^{5}$ Within 1 hr after birth. 
correspondingly, their AQ's are less than 1.0 in human fetal liver. An exception (as already observed by others (34)) is ornithine aminotransferase. Glutamate dehydrogenase is not exceptional if we consider the sum of the soluble and the particulate portions; however, in the human liver the increase with age in glutamate dehydrogenase is attributable entirely to the soluble form of the enzyme which is essentially absent from adult rat tissues (28). On the other hand, in rat as well as in human fetal liver, it is the soluble alanine aminotransferase which has a strikingly low AQ. Arginase rises with age in both species but, as recently reported (28), a portion of the activity in adult human liver is attributable to an isozyme not present in the fetus, whereas in the rat liver the fetal and the adult enzymes are indistinguishable.

Having found that in developing human liver the concentrations of the various enzymes tend to change in the same direction as they do in rat liver, we can look for more detailed analogies, at least among the larger group of enzymes, whose concentrations increase between fetal and adult life. Most of the several dozen such enzymes studied in rat liver can be classified into three main clusters, according to whether their rise begins on about the 17th day of gestation, the first neonatal day, or just before weaning, respectively. The behavior of these clusters, comprising a dozen or more enzymes each, are symbolized by curves B, C, and D in Figure 1. From each cluster several enzymes are represented in Table 1 (see letters in the last column). It may be seen that their distribution among the three clusters correlates with their $A Q$ in the human fetal liver. In general, enzymes whose $A O$ is around 0.5 belong to the late fetal cluster (B) in rat liver, whereas those with 10 or less (with the exception of cystathionase) belong to cluster $C$ or $D$ in rat liver. This indicates a species similarity with respect to the temporal sequence in which the different enzymes begin to approach their adult levels. It is noteworthy that of the two exceptions one (ornithine aminotransferase, discussed above) rises earlier and the other (cystathionase, see also Table 2) later in the human liver than expected from this general rule.

Among the hepatic enzymes quantified in the human neonate, several (first six entries in Table 2) belong to subcluster B2 in rat

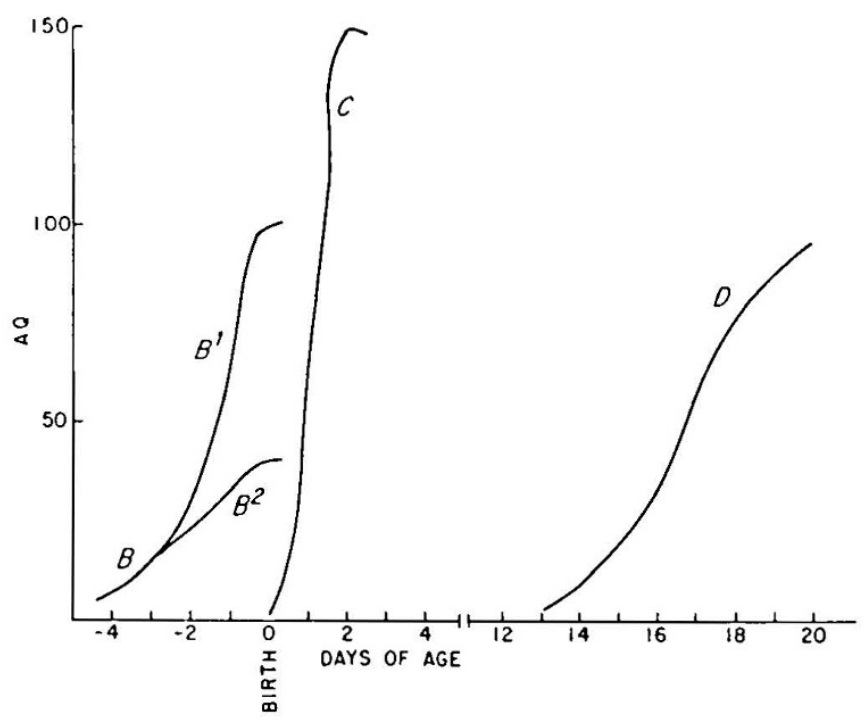

Fig. 1. Enzyme clusters in developing rat liver. Each curve symbolizes the typical developmental behavior of some 12 enzymes. Among enzymes of the late fetal cluster $(B)$, some attain their adult level at term $\left(B^{\prime 1}\right)$, others $\left(B^{2}\right)$ underge a second, postnatal upsurge either during neonatal life or shortly before weaning. Enzymes of the neonatal cluster (C) begin to rise immediately after delivery and several exhibit a temporary overshoot (lasting 1 or 2 days) of their adult level. Enzymes of the late suckling cluster $(D)$ begin their upsurge in the third postnatal week, i.e., 6-10 days before weaning. For details see reviews $(15,17)$. liver (see Fig. 1); they begin their upsurge on about the 17th day of gestation but do not attain their adult concentration by term. In human liver the initial upsurge of the same six enzymes occurred before the 12 th week and therefore their AQ's in the fetus are much higher than they are in rat liver 3 days before birth ( $c f$. Tables 1 and 2 ). However, there was little change between midgestation and term so that at birth the species difference becomes minimal: the AQ's range from $0.45-0.58$ in man and from 0.22-0.59 in the rat. Even in the case of cystathionase, the species difference may become less striking by term. Among deceased preterm or full term infants some exhibited significant activity (see range in Table 2) indicating that the enzyme may begin to accumulate during the third trimester (normal fetuses of this age have not been studied). Thus, cystathionase may not be quite as exceptional as suggested by the results of Table 1: as in the rat (and monkey (59)) so in man it may be a member (although a somewhat "delayed" one) of the late fetal cluster. Much of the accumulation of the last two enzymes in Table 2 occurs postnatally in both species. Alcohol dehydrogenase clearly exhibits similarly low AQ's at birth. Phosphoenolpyruvate carboxykinase has not been measured in man at term but remains low through at least the seventh month of gestation (53). As indicated by its AQ of 0.42 on the third postnatal day, a sudden rise may occur upon delivery, as it does in the rat. The AQ"s in the "Newborn human liver" column of Table 2 thus give the impression that at birth the liver of man and rat attains a similar degree of differentiation. It was during the last three days of gestation that the rat liver "caught up" with the development of human liver with respect to the synthesis of certain enzymes (see first six entries in Table 2) while in the third trimester human liver, the development of cystathionase began to "catch up" with that in the preterm rat liver.

\section{PHYSIOLOGIC COROLLARIES AND UNDERLYING MECHANISMS}

The time schedule of enzymic differentiation, like so many life processes, reflects an apparent purposefulness: as noted for rat and chick tissues (21), the sequential emergence of enzymes "makes sense" in terms of the changing functional requirements of the developing organism. A subtle aspect of this teleonomy can be seen in the hierarchy of hepatic functions that become operative at birth only. Depending on their importance or urgency, the corresponding enzymes develop either before, or shortly after, the event of birth. Glycogen deposition, glyeogenolysis, and urea synthesis are clearly not necessary in utero (the prenatal development of individuals with corresponding genetic deficiencies appears to be normal) but the appropriate enzymes appear before birth, in anticipation of the physiologic need. Functions such as gluconeogenesis from amino acids, fat, or lactate and detoxification via glucuronidation must be less "urgent" since the enzymes emerge some hours or days after extrauterinization as if in response to the physiologic need. A well known illustration of the biologic "sense" and economy of this arrangement is as follows: the prenatal accumulation of hepatic glycogen, phosphorylase, and glucose-6-phosphatase assures the immediate release of free glucose at birth and postpones the need for its syntheses de novo (via enzymes, like phosphoenolpyruvate carboxykinase, glycerol kinase, and transaminases) until the depletion of the hepatic glycogen store, a day or so later.

The above discussed hierarchy among enzymes is of considerable interest in connection with premature birth. Functions that develop by midgestation, in anticipation of the needs of extrauterine existence, would not be expected to limit the survival of premature babies whereas those which are still absent toward the end of gestation may. That urea cycle enzymes are as concentrated in the 20-week fetus as in the normal newborn (Table 2) is in accord with the fact that inadequate nitrogen elimination is not a usual problem encountered with genetically normal premature babies. (The very low level of urea cycle enzymes alone could explain why rats delivered 3 days, as opposed to 1 day 
before term, do not survive.) The well known perinatal problems due to the deficiency of enzymes which detexify bilirubin and drugs (9) exemplify ways in which the other group of enzymes in the hierarchy, those absent from the normal liver at term, could handicap the premature infant. The possible consequences of the late schedule of the development of cystathionase levels have also been discussed recently (60). However, if enzymes as important as phosphoenolpyruvate carboxykinase, the key catalyst of gluconeogenesis de novo, are deficient at 7 months and even at term, how is the survival of premature infants possible at all? The following discussion of the stimuli of biochemical differentiation provides a possible answer to this question.

Extensive studies on developing rat liver showed that the stepwise appearance of new groups of enzymes is causally related to sequential changes in the level of circulating endocrine factors (16). Signals responsible for initiating the synthesis of enzymes of the late fetal cluster in anticipation of the need of the newborn emanate from the pituitary. This contention is supported by a temporal correlation (the secretion of glucocorticoids and thyroxine rises abruptly on day $17(3.3)$ ), and is proven more conclusively by the fact that administration of cortisol to the fetus causes precocious rises in the levels of some enzymes, and administration of thyroxine causes rises in levels of other enzymes of the late fetal cluster (17). Enzymes of the same cluster in the human fetus are already at significant levels at midgestation, and some even at 12 weeks. This suggests that an impact of pituitary function, analogous to that in the 17-day fetal rat, is exerted on the synthetic machinery of human liver sometime before the 12 th week of gestation. Indeed, the total serum thyroxine and triiodothyronine levels of the fetus undergo a sudden increase between the 9th and 10th week of gestation (12); this may also be so for glucocorticoids since by the 3rd month the fetal plasma concentration of cortisol and cortisone is as high as at term (4). However, correlations between these endocrine events and hepatic biochemical differentiation cannot be reliably established without at least extending the enzyme measurements to younger fetuses.

The next endocrine event known to regulate gene expression in rat liver is the secretion of glucagon. Enzymes normally absent till term can be evoked by the administration of this hormone to the fetus (18). The sudden increase in plasma glucagon in the normal newborn rat (14), presumably in response to hypoglycemia upon the cessation of the cord supply of glucose, is thus the signal for the synthesis of enzymes necessary for adaptation to extrauterine existence. This is probably also true for man, since there is a rise in plasma glucagon at birth (2). It is important to note that two well studied enzymes (tyrosine aminotransferase and phosphocnolpyruvate carboxykinase) of the neonatal cluster in rat liver can be evoked not only by glucagon administration but simply by premature delivery (Delvalle and Greengard, unpublished data; Reference 68), suggesting that extrauterinization, even before term, can stimulate glucagon production. One of these enzymes, tyrosine aminotransferase, was negligible in human fetuses even at 24 weeks but exhibited strikingly high activities in those (18-week) abortuses which survived for a few hours after delivery (DelValle and Greengard, unpublished data). We interpreted this rise in tyrosine aminotransferase as one triggered by extrauterinization, presumably via secretion of glucagon. Since the $\alpha$ cells of the human pancreas are competent long before term (2), the plasma level of glucagon may indeed rise upon premature (as well as term) delivery and act as a signal for synthesis of enzymes of the neonatal cluster. The existence of such an adaptive mechanism would resolve the apparent contradiction (alluded to earlier) between the insignificant levels of some key catalysts in the 7 -month fetus and the remarkable viability of premature infants.

We have no knowledge of the postnatal age in man at which those hepatic enzymes that are still deficient in the newborn attain their adult levels. In rat liver, the final steps of biochemical differentiation, including the synthesis of enzymes necessary to cope with the solid diet, occur just before weaning (64). Some of these enzymes can be prematurely induced with cortisol, others with thyroxine, indicating that the natural resurgence of pituitary function on day 12 triggers these events. Indeed, prior to this time, there is an ebb in glucocorticoid and thyroxine secretions. Their plasma levels (which rise during the last days of gestation (7) show a trough, lasting from the 2 nd to the 10 th postnatal days $(29,61)$. This period of latency in some aspects of pituitary activity (and hepatic differentiation), accompanied by considerably body growth and cerebral maturation, was suggested to be of great advantage to the developing organism (56). In man, a somewhat similar type of latency may begin in the third month of gestation at the time when the rise in fetal thyroid and glucocorticoid hormones ceases $(4,12)$, and may last almost until term. This period, relatively uneventful from the point of view of hepatic differentiation, permits extensive body growth and the maturation of tissues other than liver. That lung must be one of the last tissues to undergo significant prenatal maturation (associated with a near term spurt in glucocorticoid availability (47)) is suggested by the high incidence of respiratory distress, the most frequent single cause of death among premature babies. Respiration is only one of many functions mandatory upon extrauterinization and yet survival appears to be limited primarily by the degree of pulmonary differentiation attained.

\section{CONCLUSION}

It is reasonable to expect that a common masterplan would underlie the process of hepatic differentiation in various mammalian species. Why then did we take the trouble to document this as objectively as possible? It was necessary to prove the obvious, because the literature abounds in statements to the effect that the maturation of hepatic functions in man is scheduled very differently from that in the rat. This view, usually based on having found that a particular enzyme was detectable at midgestation in human liver but not in rat liver, does not take into consideration the need to quantify enzymes on a physiologically meaningful scale, e'g., to define the $\mathrm{AQ}$ (often very low) of the "detectable" enzymes. The arbitrary choice of midgestation as the stage of comparison is another problem. Demonstration of the common dynamics of biologic growth (41) required transformation of the time scale to a universally applicable one: the body and organ weights of different classes of animals yielded superimposable curves if plotted against such a normalized abscissa. To depict tissue differentiation in this manner the ordinate, instead of weight units, would have to represent the overall quantitative pattern of gene products. The elements of this pattern are given by the concentration of each gene product, enzyme, normalized against that in the cognate adult tissue. An average of these quotients, termed "distance," is a measure of the degree of immaturity; only for developing rat liver has a "distance" versus age curve, quantifying the rate of biochemical differentiation, so far been depicted (36). Because of the lack of data on human liver, we cannot prove that "distance units" for the two species, against a normalized time scale, would yield superimposable curves. Hence, despite the impression that at midgestation the hepatic enzyme pattern is as mature as that of the rat 2 days before birth, the curve for the rat does not serve to extrapolate to earlier or later developmental stages of the human liver. What we could predict from the rat model is the "quality" of the immaturity of human liver, the identity of the enzymes with relatively low, medium, or very high $A Q$ 's at midgestation or term; a species similarity in the overall process of hepatic differentiation was revealed by a sequence in which various enzymes approached their mature levels.

Insofar as these species analogies extend to mechanisms which regulate specific gene expression, agents which can artificially enhance hepatic biochemical differentiation in the rat may have a similar effect in man. By the administration of appropriate hormones before the time of their natural increase in the circulation, it was possible to evoke the precocious synthesis of some two dozen enzymes in rat liver and several also in nonhepatic 
organs of experimental animals. There is one particularly good illustration of the importance of such findings. Cortisol was shown to enhance the maturation of pulmonary surfactant synthesis in late fetal lambs and rabbits $(10,39)$; when administered to pregnant women shortly before labor, it decreased the incidence of respiratory distress in premature infants (43). Natural substances or their structural analogies have not yet been used to enhance the functional maturation of human fetal liver. The (questionable) use of phenobarbital to increase the glucuronyl transferase level, and thereby the elimination of bilirubin in newborns (67), merely indicates the feasibility of precocious stimulation of enzyme synthesis in this organ.

Knowledge of the AQ's for a large number of enzymes, even if restricted to just one fetal period, can be utilized for a variety of purposes. The classification of enzymes into "early" (or "fetal") and "late" (or "adult") was instrumental, for example, in defining the biochemical counterpart of the histologic dedifferentiation of rat tumors, in grading of their neoplasticity (37), and in showing that a systemic effect of tumors (at a distant site) on host liver is to render its enzymic composition akin to that of immature liver (27). Assuming a species analogy, from the data presented here one might predict which enzymes may be at particularly high or low concentrations in human hepatomas and in the (noninvolved) livers of cancer subjects. Once the kind of information typified in Table 1 becomes available for other organs, one could select suitable enzymes, the measurement of which would contribute to the identification of the tissue or origin of various neoplasms as well as to the assessment of their malignancy.

This leads us to consider the importance of quantitative enzyme measurements in medical diagnoses. A recent study (42) which, rightly or wrongly, implicates the partial deficiency of hepatic phosphoenolpyruvate carboxykinase in the sudden infant death syndrome is important merely as a harbinger of the future when enzyme pathology will become an important part of postmortem examinations. At present tissue enzyme analysis in postmortem material is usually considered to be research unless its purpose is to confirm the diagnoses of rare inborn errors in metabolism; even then it tends to be restricted to the tissue and the enzyme that would reveal the primary genetic lesion. Indeed, it has been much easier to interpret the qualitative absence or presence of an enzyme than to evaluate quantitative deviations in several enzymes which may be associated with the developmental abnormalities not attributable to a single, aberrant gene. One difficulty is that comparison with the normal control of the same age is not sufficient. For example, 1 unit of activity (per g) of an enzyme as opposed to 3 in the control may reflect a physiologically insignificant difference, a serious delay in the synthesis, or a precocious loss in the enzyme concentration depending on whether the activity in the cognate adult tissue is 80,3 , or 0.1 units. Analysis of such results in terms of AQ's avoids this ambiguity. The choice of enzymes to be measured especially in prenatal death when no particular physiologic malfunctions could be specified, is another problem. Again, the AQ's in the normal tissue provide the clues. To diagnose inadequate growth potential and distinguish it from deficient functional differentiation we need to measure, at the appropriate age, enzymes with AQ's both well above and significantly below 1.0. Enzymes which emerge in the liver during fetal life (with AQ's around 0.5 in Table 1) would signal abnormalities in prenatal differentiation, whereas enzymes with AQ's which are still low at term would be the best indicators of inadequate maturation during early postnatal life. Some of these choices could have been predicted from the developmental behavior of enzymes in rat liver. Other tissues probably exhibit similar species analogies. The application of enzyme pathology to nonhepatic tissues may thus be guided by data available for experimental animals as well as by the gradually accumulating information about additional developing tissues in man, such as lung, intestine, etc. As the pathologist surveys all parts of the stillborn or deceased infant and not merely organs thought to be involved, an appropriate battery of enzymes should be assayed in several tissues. For example, the many instances of death due to respiratory distress could then be classified according to whether they were associated with insufficient surfactant synthesis specifically, with a generalized pulmonary immaturity, or with the inadequate differentiation of several fetal organs. Such surveys, revealing faulty or missing hormonal signals, could predict problems that may arise in future pregnancies of the same individual and suggest means of preventing them.

Gross malformations resulting from the teratogenic action of drugs, hormones, or vitamins on the early embryo attract much attention. The harmful impacts of such agents at late stages of gestation are less spectacular. They may be more frequent, however, and manifest themselves in permanent inadequacies in metabolism or growth with a tendency to succumb to minor childhood diseases. The underlying causes may not be mirrored in the cytocomposition or even the subcellular morphology of autopsy specimens. Only deviations from the organ-characteristic quantitative pattern of gene products would provide sensitive enough indicators of the metabolic lesions and of the aberrant aspects of differentiation that were responsible for them. In both the presence and absence of detectable morphologic abnormalities, the study of enzymes, this most varied and largest class of specific chemical constituents, would greatly extend the resolving power of the usual diagnostic procedures postmortem.

\section{REFERENCES AND NOTES}

1. Anderson, T. R., and Schanberg, S. M.: Ornithine decarboxylase activity in developing rat brain. J. Neurochem., 19: 1471 (1972).

2. Assan, R., and Girard, J. R.: Glucagon in the human fetal pancreas. In: R. A Camerini-Davalos and H. S. Cole: Early Diabetes in Early Life (Academic Press, New York, 1975)

3. Ballard, F. J., and Hanson, R. W.: Phosphoenolpyruvate carboxykinase and pyruvate carboxylase in developing rat liver. Biochem. J., 104: 866 (1967)

4. Beitins, I. Z., Bayard, F., Ances, I. G., Kowarski, A., and Migeon, C. J.: The metabolic clearance rate, blood production, interconversion and transplancental passage of cortisol and cortisone in pregnancy near term. Pediat. Res., 7: 509 (1973).

5. Burch, H. B., Lowry, O. H., Kuhlman, A. M., Skerjance, J., Diamant, E. R. Lowry, S. R., and von Dippe, P.: Changes in patterns of carbohydrate metabolism in the developing rat liver. J. Biel. Chem., 238: 2267 (1963).

6. Chase, H. P., Volpe, J. J., and Laster, L.: Transsulfuration in mammals: Fetal and early development of methionine-activating enzyme and its relation to hormonal influences. J. Clin. Invest., 47: 2099 (1968).

7. Cohen, A.: Plasma corticosterone concentration in the foetal rat. Hormone Metab. Res., 5: 66 (1973).

8. Dawkins, M. J. R.: Changes in glucose-6-phosphatase activity in liver and kidney at birth. Nature, 191: 72 (1961).

9. Dawkins, M. J. R.: The hazards of birth. Advan. Reprod. Physiol., 1: 217 (1966).

10. DeLomas, R., Shermeta, D. W., Knelson, J., Kotas, R., and Avery, M. E. Accelertion of the appearance of pulmonary surfactant in the fetal lamb by administration of corticosteroids. Amer. Rev. Resp. Dis., 102: 459 (1970).

11. Ditoro, R., Lupi, L., and Ansanelli, V.: Glucuronation of the liver in premature babies. Nature, 219: 265 (1968).

12. Fisher, D. A., Dussault, J. H., Hobel, C. J., and Lam, R.: Serum and thyroid gland triiodothyronine in the human fetus. J. Clin. Endocrinol. Metab., 36: 397 (1973).

13. Gaull, G., Sturman, J. A., and Räihä, N. C. R.: Development of mammalian sulfur metabolism: Absence of cystathionase in human fetal tissues. Pediat. Res., 6: 538 (1972)

14. Girard, J., Bal, D., and Assan, R.: Glucagon secretion during the early postnatal period in the rat. Hormone Metab. Res., 4: 168 (1972).

15. Greengard, O.: Enzymic differentiation in mammalian liver. Science, 163: $891(1969)$.

16. Greengard, O.: The developmental formation of enzymes in rat liver. In: G Litwack: Biochemical Actions of Hormones (Academic Press, New York, $1970)$.

17. Greengard, O.: Enzymic differentiation in mammalian tissues. Essays Biochem., 7: 159 (1971).

18. Greengard, O., and Dewey, H. K.: Initiation by glucagon of the premature development of tyrosine aminotransferase, serime dehydratase, and glucose6-phosphatase in fetal rat liver. J. Biol. Chem., 242: 2986 (1967).

19. Greengard, O., Federman, M., and Knox, W. E.: Cytomorphometry of developing rat liver and its application to enzymic differentiation. J. Cell Biol., 52: 261 (1972).

20. Greengard, O., Sahib, M. K., and Knox, W. E.: Developmental formation and distribution of arginase in rat tissues. Arch. Biochem. Biophys., 137: $477(1970)$

21. Greengard, O., and Thorndike, J.: Changing enzyme patterns in chick organs during development. Enzyme, 17: 333 (1974). 
22. Halac, E., and Sicignano, $C_{.:}$Re-evaluation of the influence of sex, age pregnancy, and phenobarbital on the activity of UIDP-glucuronyl transferaso in rat liver. J. Lab. Clin. Med., 73: 677 (1969).

23. Heinonen, K.: Studies on cystathionase activity in rat liver and brain during development: Effects of hormones and amino acids in vivon. Biochem. J. 1.36: 1011 (1973).

24. Herzfeld, A., Federman, M., and Grengard, O.: Subcellular morphometric and biochemical analysis of developing rat hepatocytes. J. Cell Biol., 57: 475 (1973)

25. Herzfeld, A., and Greengard, O.: Endecrine modification of the developmental formation of ornithine aminotransferase in rat tissues, J. Biol. Chem.. 244: $489+(1969)$

26. Herzfeld, A., and Greengard, O.: Aspartate aminotransferase in rat tissues: Changes with growth and hormones. Biochim. Biophys. Acta, 237: 88 (1971).

27. Herzfeld, A., and Greengard, O.: The dedifferentiated pattern of enzymes in livers of tumor-bearing rats. Cancer Res.. 32: 1826 (1972).

28. Herafeld, A., Rosenoer, V. M., and Raper, S. M1.: Glutamine dehydrogenase, alanine aminotransferase, thymidine kinase and arginase in fetal and adul human and rat liver. Pediat. Res., 10:960) (1976).

29. Hommes, F. A., Wilmink, C. W., and Richters, A.: The development of thyroid function in the rat. Biol. Neonat., $14: 69(1969)$

30. Jacuuet, R., and Kretelmer, N.: Effect of fetal decapitation on enzymes of glycogen metabolism. J. Biol. (hem., 239: 1301 (1964).

31. Jamdar, S. C., and Greengard, O.: Phosphoserine phosphatase: Development formation and hormonal regulation in rat tissues. Arch. Biochem. Biophys. 1.34: $228(1969)$.

32. Jamdar, S. C., and Greengard, O.: Premature formation of glucohinase in developing rat liver. J. Biol. (hem., 245: 2779) (1970).

33. Jost, A.: Problems of fetal endocrinology: The adrenal glands. Recent Prog. Hormone Res., 22: 541 (1966).

34. Kekomäki, M. P., Räihä, N. C. R., and Bickel, H.: Ornithine-ketoacid aminotransferase in human liver with reference to patients with hyperornithinatemia and familial protein intolerance. Clin. Chim. Acta, 23: 203 (1969).

35. Knox, W. E.: Two mechanisms which increase in vioo the liver tryptophan peroxidase activity: Specific enzyme adaption and stimulation of the pituitary-adrena! system. Brit. J. Exp. Pathol., 32: 462 (1951)

36. Knox, IV. L.: Enzyme Patterns in Fetal, Adult and Neoplastic Rat Tissues (S Karger, Basel, 1972).

37. Knox, WV. E.: The proteplasmic patterns of tissues and tumors. Amer. Sci., $60: 480(1972)$

38. Knox, W. E., Auerbach, V. H., and Lin, E. C. C.: Enzymatic and metabolic adaptations in animals. Physiol. Rev., 36: 164 (1956).

39. Kotas, R. V., and Avery, M. E.: Accelerated appearance of pulmonary surfactant in the fetal rabbit. J. Appl. Physiol., 30: 358 (1971).

40. Kretchmer, N.: Enzymatic patterns during development; an approach to a biochemical definition of immaturity. Pediatrics, 23: 606 (1959).

41. Laird, A. K.: Dynamies of embryonic growth. Growth, $30: 263$ (1966).

42. Lardy, H. A.: First Annual Symposium on Sudden Infant Death Syndrome (National Institute of Child Health, 1975).

43. Liggins, G. C., and Howie, R. N.: A controlled trial of antepartum glucocorticoid treatment for prevention of the respiratory distress syndrome in premature infants. Pediatrics, 50: 515 (1972).

44. Machovich, R., and Greengard, O.: Thymidine kinase in rat tissues during growth and differentiation. Biochim. Biophys. Acta, 286: 375 (1972)

45. McGee, M. M., Greengard, O., and Knox, W. E.: The quantitative determination of phenylalanine hydroxylase in rat tissues: its developmental formation in liver. Biochem. J., 127: 669 (1972).

46. Moog, F.: Developmental adaptations of alkaline phosphatases in the small intestine. Fed. Proc., 2l: 51 (1962).
47. Murphy, B. E. P., and Diez d'Aux, R. C.: Steroid levels in the human fetus: Cortisol and cortisone. J. (lin. Endecrinol. Metab., 35: 678 (1972).

48. Needham, J.: Chemical Embryology (University Press, Cambridge, England. 1931).

49. Nemeth. A. M.: Mechanisms controlling changes in tryptophan peroxidase activity in developing mammalian liver. J. Biol. Chem. 234: 292! (1959).

50. Pikkarainen, P. H., and Räihii, N. C. R.: Development of alcohol dehydrogenase activity in the human liver. Pediat. Res., 1 : 165 (1967).

51. Räihï, N. C. R.: Phenylalanine hydroxylase in human liver during development. Pediat. Res., 7: 1 (1973)

52. Räihä, N. C. R., Koskinen, M., and Pikharainen, P.: Developmental changes in alcohol-dehydrogenase activity in rat and guinea-pig liver. Biochem. J., 10)3: $62.3(1967)$.

53. Räihä, N. C. R., and Lindros, K. O.: Development of some enzymes involved in gluconeogenesis in human liver. Ann. Med. Exp. Biol. Fenn., 47: 146 $(1969)$.

54. Räihä, N. C. R., and Suihkonen, J.: Development of urea-synthesizing enzymes in human liver. Acta Paediat. Scand., 57: 121 (1968).

55. Räihä, N. C. R., and Suhkonen, J.: Factors influencing the development of urea-synthesizing enzymes in rat liver. Biochem. J., 107: 793 (1968).

56. Schapiro, S.: Some physiological, biochemical, and bebavioral consequences of neonatal hormone administration: Cortisol and thyroxine. Gen. Comp. Endocrinol., 10: $214(1968)$.

57. Schwartz, A. L., Räihä, N. C. R., and Ratl, T. W.: Effect of dibutyryl cyclic ANP on glucose-6-phosphatase activity in human fetal liver explants. Biochim. Biophys. Acta, 343: 500 (1974).

58. Sturman, J. A., and Gaull, G. E.. Polyamine biosynthesis in human fetal liver and brain. Pediat. Res., 8: 231 (1974).

59. Sturman, J. A., Gaull, G. E., and Niemann, W. H.: Cystathionine synthesis and degradation in brain. liver and kidney of the developing monkey. J. Neurochem., 26: 457 (1976).

60). Sturman, J. A., Gaull, G. E., and Räihä, N. C. R.: Absence of cystathionase in human fetal liver: Is cystine essential'? Science, 169: 74 (1970)

61. Taylor M. .1. and Howard, E. Impaired glucose homeostasis in adult rats after corticosterone treatment in infancy. Endocrinolugy, 88: 1190 (1971).

62. Ureta, T., Bravo, R., and Babul, J.: Rat liver hexokinase during development. Enzyme, 20: 334 (1975).

6.3. Vernon, R. G., and Walher, D). (B.: (hanges in activity of some culymes involved in glucose utilization and formation in developing rat !iver. Biochem. J., 106: 321 (1968).

64. Vernon, R. G., and Wather, 1). G.: Adaptive behaviour of some enzymes involved in glucose utilization and formation in rat liver during the wearning period. Biochem. J., 106: 331 (1968).

65. Vogel, W. H., Bechme, D. H., and Salerno, N. J.: Activities of tyrosine aminotransferase in various human tissues. J. Neurochem., 21: 705 (1973).

66. Volpe, J. J., and Laster, L.: Transsulfuration in fetal and postnatal mammalian liver and brain. Biol. Neonate, 20: 385 (1972).

67. Yeung, C. Y., Iam, L. S., Chan, A., and Lee, K. H.: Phenobaritone prophylaxis for neonatal hyperbilirubinemia. Pediatries, 48: 372 (1971).

68. Yeung, D., and Oliver, I. T.: Factors affecting the premature induction of phosphopyruvate carboxylase in neonatal rat liver. Biochem. J.. 108: 325 (1968).

69. This investigation was supported by United States Public Health Service Grant CA 08676 from the National Cancer Institute, and by the United States Energy Research and Development Administration Contract EY-76-S-(123085. A001 with the New Fingland Deaconess Hospital.

70. Requests for reprints should be addressed to: (O. Cirengard, Ph.D. Cancer Research Institute, New England Deaconess Hospital, 185 Pilgrim Road, Boston, Mass. (22215 (USA).

71. Received for publication July 27, 1976.

72. Accepted for publication October 6, 1976. 